\title{
Analysis on Influencing Factors of Entrepreneurial Environment of College Students Based on PEST Model
}

\author{
Yinying Zhang ${ }^{1}$, Xionglin Lai $^{1}$ \\ ${ }^{1}$ Xi'an University of Science and Technology, Xi'an, 710054, China
}

Keywords: Entrepreneurial environment. Indicator System. College Students

\begin{abstract}
This paper studies the entrepreneurial environment of college students in China currently and analyzes advantages and disadvantages of college students' entrepreneurship under the current complicated situation, which are problems to be faced by entrepreneurial education and are conducive to more effective implementation of college students' entrepreneurship. This paper establishes a quantitative indicator evaluation system according to practical conditions of entrepreneurial environment in Shaanxi based on macro-environment (PEST). The research and evaluation allow students to know dominant factors and secondary factors influencing entrepreneurial environment and their degree of influence so as to draw a clear distinction between the primary and the secondary and shoot the arrow at the target during the implementation of entrepreneurship. It is also good for the government and colleges and universities to improve entrepreneurial environment to the maximum extent under the environment of resource constraint.
\end{abstract}

\section{Introduction}

Entrepreneurship is a complicated activity process. It is influenced by micro-and macro-environmental factors. Entrepreneurial performance refers to entrepreneurial subjects' way of obtaining and ability of using entrepreneurial resources and rein and application of micro- and macro-environmental factors. This paper establishes a quantitative indicator evaluation system according to practical conditions of entrepreneurial environment in Shaanxi based on macro-environment (PEST) and analyzes influencing factors of entrepreneurial environment of college students.

PEST model is a method used to analyze external macro-environment of enterprises, including main external environmental factors of political, economic, social and technological enterprises. This paper refines social and technological factors according to differences between entrepreneurship of enterprises and college students by using PEST model, analyzes entrepreneurial phenomena from policy, economy, education and morality, emphasizes entrepreneurial education and culture based on educational resources of Shaanxi Province, specifies the current macro-environment of competition of entrepreneurship with the analytical framework of this method, further analyzes the relationship between entrepreneurial environment and opportunities, which are good for students to analyze entrepreneurial activities more effectively, and thus provides certain theoretical reference for college students' entrepreneurship and evaluation of entrepreneurial opportunities and environmental factors.

\section{Research on contents of evaluation system}

\section{Principles of design of evaluation indicators}

The design of evaluation indicators is a main link after the establishment of evaluation objectives. The scientificalness and rationality of indicator system design directly concern the accuracy and objectivity of evaluation. To describe entrepreneurial environment specifically, it is required to establish a complete framework which should meet the following requirements: first, sense of identity. All factors constituting entrepreneurial environment can be identified by interested parties, which is conducive to the realization of objectives. Second, comparability. Subitems listed must be as specific as possible and easily measured. Third, adaptation. Subitems listed should have certain logic. This paper refines social and technological factors according to differences between entrepreneurship 
of enterprises and college students by using PEST model, analyzes entrepreneurial phenomena from policy, economy, education and morality, emphasizes entrepreneurial education and culture based on educational resources of Shaanxi Province and specifies the current macro-environment of competition of entrepreneurship with the analytical framework of this method.

\section{Establishment of indicator system}

This paper establishes an evaluation indicator system of entrepreneurship according to our design thought and evaluation principles based on the principle that the selection and design of indicators should reflect relative stability, conciseness, acquisitiveness and operability. This indicator system includes four first-grade indicators and 16 second-grade indicators (for details, see table 3-1).

\section{Contents of evaluation indicator system}

\begin{tabular}{|c|c|c|c|}
\hline $\begin{array}{l}\text { First-grade } \\
\text { indicators }\end{array}$ & $\begin{array}{l}\text { Second-grade } \\
\text { indicators }\end{array}$ & Third-grade indicators & Judgment method \\
\hline \multirow{9}{*}{$\begin{array}{l}(25 \%) \\
\text { Policy level } \\
(25 \%)\end{array}$} & \multirow{2}{*}{$\begin{array}{l}\text { Financial } \\
\text { support } 40 \%\end{array}$} & $\begin{array}{l}\text { Total amount of venture capitals } \\
\text { set up by the government }\end{array}$ & \\
\hline & & $\begin{array}{l}\text { Total amount of micro loan for } \\
\text { entrepreneurship provided by } \\
\text { bank }\end{array}$ & \\
\hline & \multirow{2}{*}{$\begin{array}{l}\text { Project } \\
\text { support 35\% }\end{array}$} & $\begin{array}{l}\text { Fund, quantity and scale of } \\
\text { special projects directly provided } \\
\text { by the government }\end{array}$ & \\
\hline & & $\begin{array}{l}\text { Quantity and scale of projects } \\
\text { provided for entrepreneurs by the } \\
\text { government with social resources }\end{array}$ & \\
\hline & \multirow{2}{*}{$\begin{array}{l}\text { One-stop } \\
\text { entrepreneurs } \\
\text { hip 5\% }\end{array}$} & $\begin{array}{l}\text { Working formalities required for } \\
\text { the examination and approval of } \\
\text { new enterprises }\end{array}$ & \\
\hline & & $\begin{array}{l}\text { Costs to be paid for the } \\
\text { examination and approval of new } \\
\text { enterprises }\end{array}$ & \\
\hline & \multirow{2}{*}{$\begin{array}{ll}\text { Tax } & \text { support } \\
10 \% & \end{array}$} & $\begin{array}{l}\text { Items subject to tax deduction } \\
\text { and exemption and preferential } \\
\text { policies }\end{array}$ & \\
\hline & & $\begin{array}{l}\text { Purchase of products of } \\
\text { entrepreneurial enterprises by the } \\
\text { government }\end{array}$ & \\
\hline & $\begin{array}{l}\text { Entrepreneurs } \\
\text { hip with social } \\
\text { protection } \\
20 \%\end{array}$ & $\begin{array}{l}\text { Establishment of exit channel of } \\
\text { enterprises failing in } \\
\text { entrepreneurship }\end{array}$ & \\
\hline \multirow{8}{*}{$\begin{array}{l}\text { Economic } \\
\text { level }(25 \%)\end{array}$} & \multirow{2}{*}{$\begin{array}{l}\text { Economic } \\
\text { growth } 15 \%\end{array}$} & GDP per capita & \\
\hline & & GDP growth rate & \\
\hline & \multirow{3}{*}{$\begin{array}{l}\text { Market } \\
\text { requirement } \\
40 \%\end{array}$} & $\begin{array}{l}\text { Opening rate of small and } \\
\text { medium-sized enterprises }\end{array}$ & \\
\hline & & $\begin{array}{l}\text { Close rate of small and } \\
\text { medium-sized enterprises }\end{array}$ & \\
\hline & & Survival rate of entrepreneurship & \\
\hline & \multirow[t]{2}{*}{$\begin{array}{l}\text { Consumption } \\
10 \%\end{array}$} & $\begin{array}{l}\text { Average annual growth rate of } \\
\text { disposable income of residents }\end{array}$ & \\
\hline & & $\begin{array}{l}\text { Average annual growth rate of } \\
\text { consumption in recent } 3 \text { years }\end{array}$ & \\
\hline & Investment & Average annual growth rate of & \\
\hline
\end{tabular}




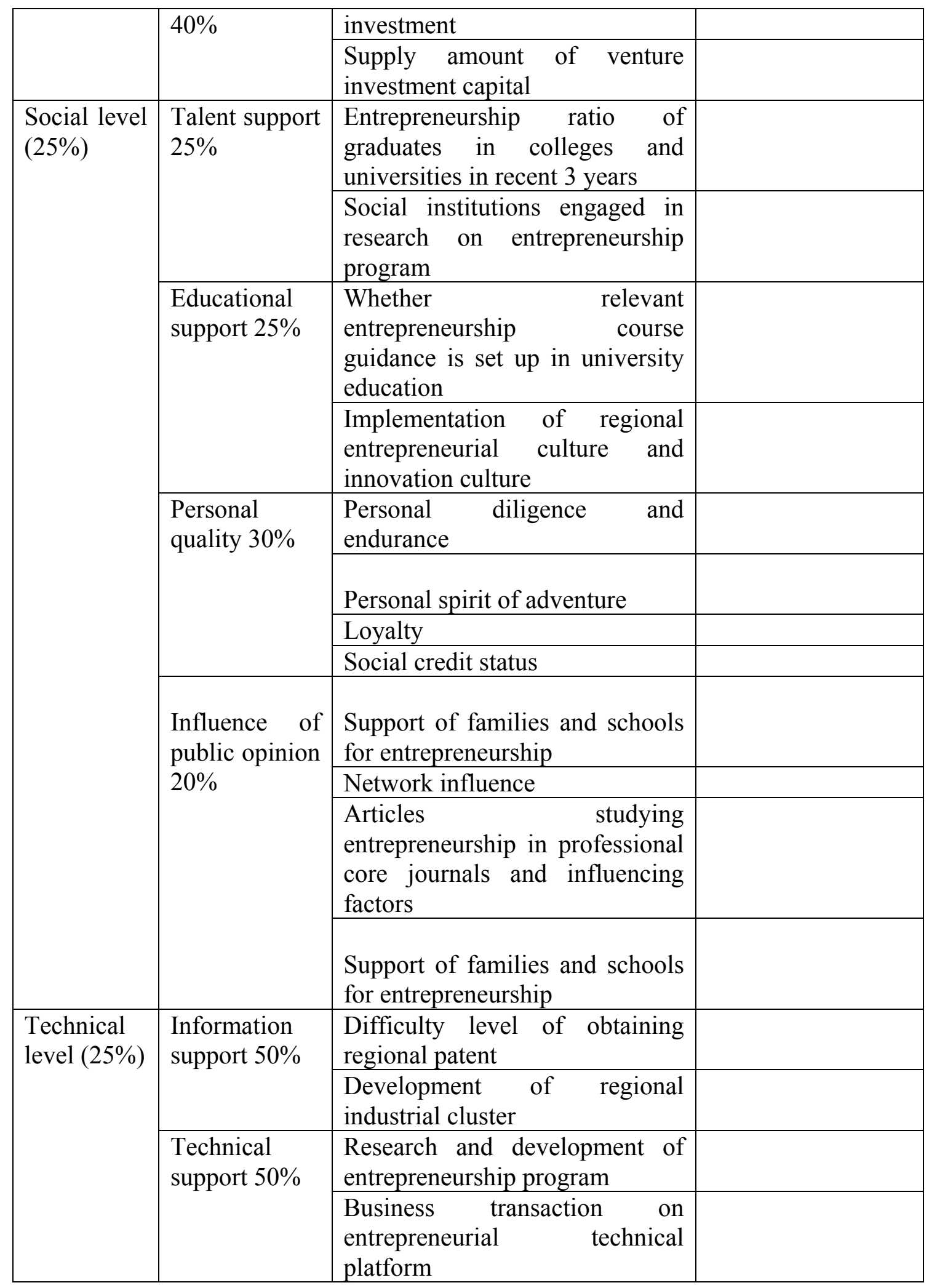

\section{Evaluation methods}

For all indicators, two steps are taken to calculate the total assessment score:

Step 1: select indicators, arrange single indicators respectively according to indicators themselves and their variation, calculate individual points according to the proportion and calculate the total assessment score of each individual point according to weight.

Step 2: calculate the assessment score of the target plan.

Step 3: entrepreneurial environment index $=\Sigma X n Y n=X 1 Y 1+X 2 Y 2 \ldots \ldots+X 35 Y y 35$ 
Figures in brackets in table 1 refer to the weight of this indicator in superior index. It is necessary to explain that the rationality of each indicator inevitably has the possibility of deviation due to limited research ability of the author. Weights of policy level, economic level, social level and technical level in the overall evaluation indicator system of entrepreneurial environment are respectively 0.20 . Weights of sub-indicators in each investigation field are shown specifically in table 1. Thus, the computational formula of entrepreneurial environment index can be obtained: in the computational formula, $\mathrm{X}$ refers to indicator, $\mathrm{Y}$ refers to the weight of indicator in the overall indicator system and $\mathrm{n}$ refers to the serial number of indicator weight. This paper will obtain the influence degree of indicators above in the entrepreneurial process of college students according to expert scoring method and entrepreneur questionnaire and through scientific measurement.

\section{Conclusions of comprehensive indicator evaluation and score calculation}

Final conclusions of performance evaluation are made from performance evaluation of entrepreneurial environment in Shaanxi according to evaluation indicator system in table 1.

\begin{tabular}{|l|l|l|l|l|}
\hline Ranking & Factor & $\begin{array}{l}\text { Indicator } \\
\text { evaluation } \\
\text { score }\end{array}$ & $\begin{array}{l}\text { Indicator } \\
\text { weight }\end{array}$ & $\begin{array}{l}\text { Score of comprehensive } \\
\text { performance evaluation }\end{array}$ \\
\hline 1 & $\begin{array}{l}\text { Economic } \\
\text { level }\end{array}$ & 2 & $25 \%$ & 0.5 \\
\hline 2 & Policy level & 1.6 & $25 \%$ & 0.4 \\
\hline 3 & Social level & 1.55 & $25 \%$ & 0.3875 \\
\hline 4 & Technical level & 1.5 & $25 \%$ & 0.375 \\
\hline
\end{tabular}

According to the comprehensive evaluation, we can see that economic level has the highest score in the evaluation system of entrepreneurial environment, followed by policy factors, social factors and technical factors.

\section{Analyze entrepreneurial environment of college students in Xi'an based on comprehensive performance evaluation}

\section{Economic environment}

Economic factors refer to the economic system, economic structure, industrial distribution, status of resources, economic development level and future economic trend of a nation. According to Economic Operation of Xi'an in the First Half of 2013 in Xi'an Statistical Bureau, the economy in $\mathrm{Xi}$ ' an presented a trend of "steady economic operation and modest recovery of increase speed of main indicators" in the first half of 2013. The total output value of Xi' an was 203.325 billion Yuan in the first half of 2013, with a year-on-year growth of $11.3 \%$. The total volume of retail sales of consumer goods was 118.945 billion Yuan and disposable income per capita of urban residents was 16,258 Yuan. In terms of industry, the added value of the primary industry was 7.925 billion Yuan, increasing by $3.0 \%$; that of the secondary industry was 87.838 billion Yuan, increasing by $15.4 \%$; that of the tertiary industry was 107.562 billion Yuan, increasing by $8.5 \%$. Market demands of entrepreneurship of college students have good prospects. The rationality of household consumption level might drive the emergence of new entrepreneurship program. Tertiary industry is still the main place for the employment and entrepreneurship of college students.

College students can investigate industrial characteristics and analyze industry market according to the trend of economic development and find out an appropriate entrepreneurship program. In terms of the development level of each industry in Xi'an, in the first half of the year, the added value of industrial enterprises above designated size was 57.389 billion Yuan. In terms of products, among 55 products monitored particularly, 32 products had year-on-year growth. Steel increased by $42.4 \%$, furniture increased by $89.1 \%$, automobile engine increased by $94.2 \%$ and automobile increased by $29.8 \%$. Truck increased by $14.4 \%$ and saloon car increased by $41.8 \%$. This can provide pertinent reference for college students starting a business in the field of energy and industry. In tourism market, the domestic tourism was relatively flourishing. 43.4244 million person-time domestic tourists were received. This indicator shows that tourism market demands are stable and college students can give 
more consideration to programs related to tourism during entrepreneurship. In addition, a batch of market demand points will occur in the process of stable and balanced economic development. In the first half of 2013, consumer price increased slightly. Consumer price increased by $2.6 \%$ on year-on-year basis. In terms of category, consumer price of food increased by $4.0 \%$ on year-on-year basis; tobacco and wine and articles for use, 2.1\%; clothing, 4.6\%; household equipment and maintenance service, $4.0 \%$; medical care and personal products, 2.3\%; articles for entertainment, education and culture, $1.3 \%$; residence, $3.0 \%$. Consumer price of transport and communication decreased by $2.7 \%$ on year-on-year basis. Market demand point accompanies consumption. Under the condition without core technology, college students can consider entrepreneurship program in clothing and food industries, which might be easier. In short, college students can select an appropriate industry for entrepreneurship under the opportunity of good economic momentum based on market with user demand as core, endeavor to explore new entrepreneurial ideas and concepts, conduct corresponding scientificalness and rationality survey and finally realize entrepreneurship.

\section{Political environment}

Political environment is connected to the act of government to a certain extent, i.e. refers to political force having actual and potential influence on business activities of an organization and relevant laws and regulations. Xi'an has implemented 'Xi'an Entrepreneurial Engineering Plan for Young Scientific and Technological Talents". With the guidance of government funds, the initiative of young scientific and technological talents for entrepreneurship has been stimulated. In investment field, Xi' an High-tech Zone has designed different fund supply ways in allusion to different stages of enterprise growth and absorbed capital investment, including entrepreneurial funds for young scientific and technological talents with an annual scale of 10 million Yuan. By the end of 2011, the number of investment and risk institutions in the zone constantly increased. Assurance service center and guarantee fund were established. This provides effective guarantee for difficult financing and shortage of funds of college students and allows college students to discover new opportunities, guide new demands, exploit niche market and explore entrepreneurial opportunities in the field of market and consumers according to relevant situations in entrepreneurship.

\section{Social environment}

Social factors refer to national characteristics, cultural tradition, value, religious belief, educational level and customs of members in the society where the organization is. Shaanxi is a major province of both education and culture. It has abundant technical talents and cultural resources, such as red culture and Qin culture and derived cultural industry. These factors provide a wide market selection room for college students' entrepreneurship. In recent years, as Qujiang New District and High-tech Zone have positively promoted regional innovative culture, e.g. High-tech Zone has vigorously promoted credibility culture, Xi'an High-tech Zone was rated as one of the 50 districts with integrity and safety of investment environment in China in 2003. This provides safe guarantee for college students' entrepreneurship. Meanwhile, colleges and universities can set up relevant courses with these resources in the education of entrepreneurship, train students' consciousness of entrepreneurship and entrepreneurial ability, and integrate these abundant cultural resources into entrepreneurial system. For example, colleges and universities can use red resources for publicity, thus allowing college students to deeply understand revolutionary spirit of hard struggle, improve their psychological and physiological quality, correctly understand risks and setbacks in the entrepreneurial process and correctly evaluate various problems under market mechanism. With abundant teacher resources, alliance of colleges and universities and implementation of venture contest, a good entrepreneurial atmosphere can form, which is conducive to the exchange learning of college students.

\section{Technical factors}

Technical factors include not only those inventions causing revolutionary changes, but also the occurrence, development trend and application prospect of new technologies, new process and new materials related to enterprise production. Xi'an has been constantly improving the ability of technological innovation and the level of innovative urban construction. According to data of the second national R\&D resource inventory work, R\&D funds of Xi' an was 16.499 billion Yuan in 2009, 
only second to Guangzhou among 14 vice-provincial cities investigated. As technical industry gathering place, Xi'an High-tech Zone has established multiple comprehensive and professional incubators and public technical service platform and established low-cost and high-quality resource sharing service and professional support platform for innovative entrepreneurship of high-level talents. This makes college students to be bold to and able to start a business and succeed. Xi'an Janssen, Dongsheng Pharmacy, Haitian Antenna, Philips, Fujitsu, Huawei, ZTE and Samsung in the zone not only consolidate the actual strength of Xi'an High-tech Zone in scientific and technological research and development, but also makes the entrepreneurial environment in $\mathrm{Xi}$ ' an have a wider market. College students can choose an appropriate entrepreneurial opportunity according to market demands under a good technical environment.

\section{Conclusion}

New cash theory points out: to increase the water capacity of cask, it is required to not only find out and lengthen the short slab, but also check the material of the cask bottom and hoop and coupling degree between the bottom and slabs. Just as cask theory, to optimize the entrepreneurial environment of college students, it is required to create a good atmosphere for college students' entrepreneurship based on social environmental construction; improve the competency of college students in entrepreneurship with the construction of educational technical environment as key; and improve the supporting system of college students' entrepreneurship with the construction of policy environment as guarantee. Political, economic, social and technical factors are essential to college students' entrepreneurship. They are an entirety with dialectical unity and interact and restrain each other. According to the analysis on entrepreneurial environment in Xi'an, we can see that Xi' an has good regional cultural environment, project environment and policy environment, which are good for motivating that initiative of students in entrepreneurship. College students can choose entrepreneurial opportunities better according to market demands and strengthen their foundation construction to realize entrepreneurship better.

\section{Acknowledgments}

This paper is the segmental results of Shannxi regular institutions of higher learning philosophy and social science disciplines construction project Local Higher Institutions Entrepreneurship Education System Research.

\section{References}

[1] Yao Meifang, Zhang Lan, Ge Jing, Huang Jinrui: Establishment of Survival-type Entrepreneurial Environment Factor System Based on Chinese Context. Forecast. Orecasting. 2010 Vol.5: 31-36

[2] Liu Zhongwen, Jiang Xiaoran, Zhang Xuping: Establishment of Evaluation Indicator System and Model of Chinese Regional Technical Innovation Ability. Technical Economy and Management Research. 2009 Vol.1: 32-35.

[3] Xu Yingyun: Research on Influence of Patent Application on College Students' Employment and Entrepreneurship. Journal of North China Electric Power University (Social Sciences Edition). April 2012 Vol.2: 120-123.

[4] Kong Huifang: Research on Wuhan Entrepreneurial Environment Based on PEST Model. Master's Thesis in Huazhong University of Science and Technology. 29 October 2011. 